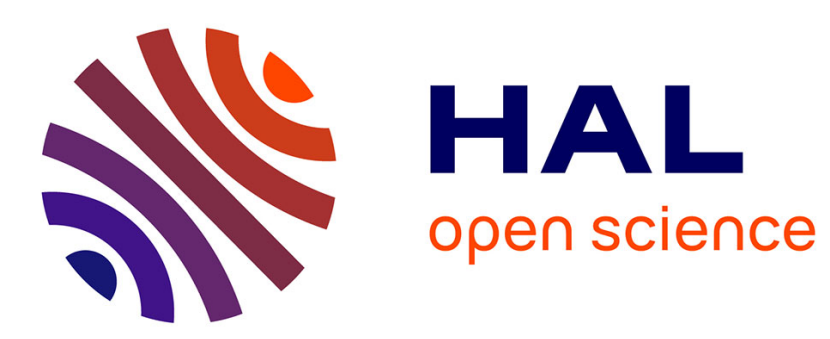

\title{
H2NSi radical: structures, isomerisation pathways and electronic states characterization
}

\author{
Majdi Hochlaf, Gilberte Chambaud, Maria Luisa Senent
}

\section{To cite this version:}

Majdi Hochlaf, Gilberte Chambaud, Maria Luisa Senent. H2NSi radical: structures, isomerisation pathways and electronic states characterization. Molecular Physics, 2010, 108 (10), pp.1277-1284. 10.1080/00268971003660163 . hal-00598956

\section{HAL Id: hal-00598956 https://hal.science/hal-00598956}

Submitted on 8 Jun 2011

HAL is a multi-disciplinary open access archive for the deposit and dissemination of scientific research documents, whether they are published or not. The documents may come from teaching and research institutions in France or abroad, or from public or private research centers.
L'archive ouverte pluridisciplinaire HAL, est destinée au dépôt et à la diffusion de documents scientifiques de niveau recherche, publiés ou non, émanant des établissements d'enseignement et de recherche français ou étrangers, des laboratoires publics ou privés. 


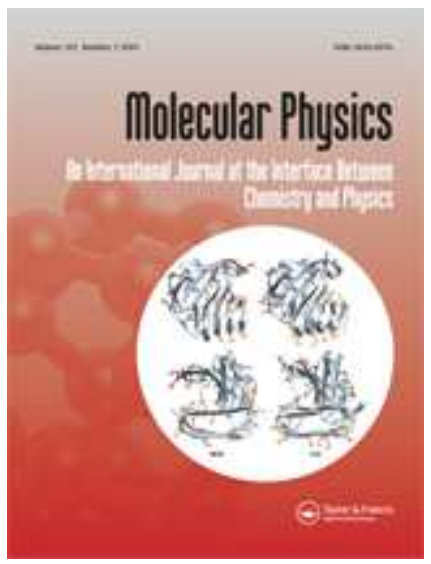

\section{H2NSi radical: structures, isomerisation pathways and electronic states characterization}

\begin{tabular}{|r|l|}
\hline Journal: & Molecular Physics \\
\hline Manuscript ID: & TMPH-2009-0357.R1 \\
\hline Manuscript Type: & Full Paper \\
\hline Author: & 24-Dec-2009 \\
\hline Complete List of Authors: & $\begin{array}{l}\text { Hochlaf, Majdi; University of Marne La Vallee, Laboratoire de Chimie } \\
\text { Theorique } \\
\text { Gilberte, Chambaud; Université de Marne la Vallée } \\
\text { Senent, Maria Luisa; IEM-CSIC, DAMIR }\end{array}$ \\
\hline $\begin{array}{r}\text { Keymords: } \\
\text { ab initio calculations, electronic states, isomers, spectroscopy, } \\
\text { silicon compounds } \\
\text { to PDF. You must view these files (e.g. movies) online. }\end{array}$ \\
\hline New WinZip File.zip \\
\hline \hline
\end{tabular}

\section{S ScholaroNE Manuscript Central}




\title{
$\mathrm{H}_{2} \mathrm{NSi}$ radical: structures, isomerisation pathways and electronic states characterization*
}

\author{
M. Hochlaf ${ }^{\text {a) }}$ \\ Université Paris-Est, Laboratoire de Modélisation et Simulation Multi Echelle, MSME FRE 3160 \\ CNRS, 5 boulevard Descartes, 77454 Marne-la-Vallée, France \\ E-mail: hochlaf@univ-mlv.fr \\ G. Chambaud \\ Université Paris-Est, Laboratoire de Modélisation et Simulation Multi Echelle, MSME FRE 3160 \\ CNRS, 5 boulevard Descartes, 77454 Marne-la-Vallée, France \\ E-mail: chambaud@univ-mlv.fr

\section{L. Senent} \\ Departamento de Astrofísica Molecular e Infrarroja, Instituto de Estructura de la Materia, C.S.I.C., \\ Serrano 121, Madrid 28006, SPAIN \\ E-mail: senent@iem.cfmac.csic.es
}

\footnotetext{
a) Author for correspondence.

* dedicated to the memory of Pavel Rosmus.
} 


\begin{abstract}
Using state-of-the-art theoretical methods, we investigate the stable isomers of $\mathrm{H}_{2} \mathrm{NSi}$ which are relevant for astrophysics, astrochemistry and ammonia silicon surface chemistry. These computations are performed using configuration interaction $a b$ initio methods and the aug-cc-pVQZ and cc-pVQZ basis sets. Our calculations confirm the existence of three stable isomers: $\mathrm{H}_{2} \mathrm{NSi}$, trans$\mathrm{HSiNH}$ and $\mathrm{H}_{2} \mathrm{SiN}$. We give the intramolecular isomerisation and the $\mathrm{H}$-abstraction reaction pathways on the lowest doublet potential energy surfaces. Insight into the pattern of the lowest doublet and quartet electronic states of these molecular species are also presented.
\end{abstract}




\section{INTRODUCTION}

The importance of the silicon-nitrogen bearing compounds is related mainly to the involvement and the role of: (i) silicon atom and ions in the chemistry of the low Earth atmosphere [16] and of the ionosphere [7]. (ii) Silicon in astrophysical media either embedded in grains or in gas phase. This domain gained in interest since the detection of $\mathrm{SiN}$ in the outer circumstellar envelope IRC +10216 in 1992 by Turner [8] (iii) Silicon atoms and $\mathrm{Si}^{+}$ions in gas phase and porous glass surfaces reactivity against ammonia for the production of a wide variety of $\mathrm{Si}_{\mathrm{x}} \mathrm{N}_{\mathrm{y}} \mathrm{H}_{\mathrm{z}}$ molecules and for catalysis [9-11]. (iv) Such molecules in the formation of polysilane materials [12] with, for instance, non linear optics properties. Therefore, $\mathrm{Si}_{\mathrm{x}} \mathrm{N}_{\mathrm{y}} \mathrm{H}_{\mathrm{z}}$ molecules (with small $\mathrm{x}, \mathrm{y}$ and $\mathrm{z}$ numbers), such as $\mathrm{H}_{2} \mathrm{NSi}$ radicals of interest here, represent the milestones for this rich and complex chemistry and for its applications.

The $\mathrm{H}_{2} \mathrm{NSi}^{+}$positively charged ionic species were widely studied. In a series of papers by Parisel, Hanus and Ellinger [11,13-15], they characterized three stable forms, namely $\mathrm{HSiNH}^{+}$, $\mathrm{H}_{2} \mathrm{NSi}^{+}$and $\mathrm{H}_{2} \mathrm{SiN}^{+}$, using multiconfigurational, Møller-Plesset MPn $(\mathrm{n}=2,3,4)$ and Coupled Clusters approaches. They derived the IR and $\mu \mathrm{w}$ spectra of these cations in order to assign the available experimental data and for predictive purposes for astrophysical detections (See Refs. $[11,13,15]$ for more details). In contrast, very few is known on the structure, the isomers, the energetics and the spectroscopy of the $\mathrm{H}_{2} \mathrm{NSi}$ neutral tetratomic molecule. This is related to the difficulty to study theoretically open shell molecular systems and to describe correctly their electronic wavefunctions. Moreover, previous works [15] reported: 1) the complexity of the generation of their vibrational spectra. 2) Their floppiness along some internal coordinates (e.g. SiN bond). 3) The difficulty of their isolation in laboratory. 4) Their spontaneous reactivity. Briefly, we can mention the mass spectrometric investigations of Goldberd et al. [16] and of Chen et al. [17], which suggested the formation of $\mathrm{HSiNH}$ and $\mathrm{H}_{2} \mathrm{NSi}$ either after neutralisation of their respective ions or through reactive collisions between $\mathrm{N}$ and $\mathrm{SiH}_{4}$. These identifications were supported by DFT structure calculations [16-18].

In the present paper, we characterize the stable isomers of $\mathrm{H}_{2} \mathrm{NSi}$ by means of state-of-the-art mono and multiconfigurational ab initio approaches and extended basis sets. For these species, we derive a set of accurate spectroscopic parameters including their rotational and vibrational terms. Moreover, we study the intramolecular isomerisation and the $\mathrm{H}$-abstraction processes. Finally, we give insight into the pattern of the doublet and the quartet electronic excited states of these tetratomic species in the $0-6 \mathrm{eV}$ internal energy ranges.

\section{COMPUTATIONAL DETAILS}


Electronic structure calculations have been achieved with the MOLPRO program suite [19]. For these computations, the cc-pVQZ and aug-cc-pVQZ Dunning's basis sets were employed $[20,21,22]$.

We searched for stationary points determining equilibrium geometries and a set of first order spectroscopic parameters (rotational constant, harmonic wavenumbers, dipole moments) at the coupled cluster level including perturbative treatment of triple excitations (RCCSD(T)) [23] and using the standard options in MOLPRO.

We investigated the low lying electronic states of the stable forms of the $\mathrm{H}_{2} \mathrm{NSi}$ sum formula with the complete active space self consistent field method (CASSCF) [24,25], followed by internally contracted multi-reference configuration interaction (MRCI) [26,27] approach implemented in MOLPRO [19]. For the CASSCF calculations, all valence molecular orbitals were optimized and all electrons were correlated. For each isomer, the doublets were averaged together and the quartets were averaged together. For MRCI, we took into account all the configurations of the CI expansion of the CASSCF wavefunctions as a reference. For instance, more than $5 \times 10^{8}$ uncontracted configuration state functions (CSFs) per $\mathrm{C}_{2 \mathrm{v}}$ symmetry result when computing the doublet states.

Calculations were carried out in the $\mathrm{C}_{1}, \mathrm{C}_{\mathrm{s}}$ and $\mathrm{C}_{2 \mathrm{v}}$ point groups. In $\mathrm{C}_{2 \mathrm{v}}$ symmetries, the molecule in lying in the $\mathrm{xz}$ plane and the $\mathrm{C}_{2}$ axis coincides with the $\mathrm{z}$ axis allowing the designation of the electronic states. In tables and figures, relative energies are given with respect to that of the most stable isomer ground state equilibrium geometry, except if précised.

\section{RESULTS AND DISCUSSION}

\section{Stable isomers}

Figure 1 displays the one-dimensional evolution of HSiNH ground doublet potential energy surface along the torsion coordinate, $\tau$. These calculations were performed with CASSCF, MRCI, MRCI+ Davidson correction (MRCI+Q) [28]) and RCCSD(T). One can clearly see a minimum corresponding to the trans-HSiNH (dihedral torsion angle $\tau=180^{\circ}$ ) isomer II (Figure 2). At the CASSCF level, a second local minimum is found for $\tau=0$ (cis configuration) and a transition state for $\tau \sim 80^{\circ}$. Both, the cis minimum and the transition state connecting cis to trans structures, vanish when larger calculations are employed, especially when the dynamical correlation is considered. For the isovalent $\mathrm{HCNH}$ molecule, a cis form, however, exists and it is located at $4.9 \mathrm{kcal} / \mathrm{mol}$ above the trans isomer [29]. For that reason, we use $\operatorname{RCCSD(T)~for~the~prediction~of~the~structural~and~spectroscopic~}$ properties of the $\mathrm{H}_{2} \mathrm{NSi}$ radicals in their ground electronic states.

At the RCCSD(T) level of theory, three stable isomers are found. They are depicted in Figure 2. The most stable form is $\mathrm{H}_{2} \mathrm{NSi}$ of $\mathrm{C}_{2 \mathrm{v}}$ symmetry (denoted by isomer I) followed then by trans- 


\section{Isomerization pathways} with the MP2/6-31G** calculations of Goldberg et al. [16] and with the recent predictions of Chen et al. [17] obtained with B3LYP/6-311++G(3df,2p). Nevertheless, different assignments are given for the nature of the ground electronic states for the $\mathrm{C}_{2 \mathrm{v}}$ species. Indeed, Goldberg et al. predict a ${ }^{2} \mathrm{~A}_{1}$ space symmetry, whereas Chen et al. found a ${ }^{2} B_{2}$ symmetry instead. Our calculations support the results of Chen et al. [17] and the full investigation of the pattern of the lowest electronic states of $\mathrm{H}_{2} \mathrm{NSi}, \mathrm{HSiNH}$ and $\mathrm{H}_{2} \mathrm{SiN}$ (cf. infra) confirms these attributions. For the $\mathrm{H}_{2} \mathrm{CN}$ isovalent systems, a ${ }^{2} \mathrm{~B}_{2}$ ground state was computed by Puzzarini and Barone for the $\mathrm{C}_{2 \mathrm{v}}$ structures [29].

Table 1 reports the RCCSD(T)/aug-cc-pVQZ equilibrium geometries for the three $\mathrm{H}_{2} \mathrm{NSi}$ isomers found presently. For isomer I, our equilibrium geometry is: $R_{\mathrm{NH}}=1.010 \AA, \mathrm{R}_{\mathrm{SiN}}=1.712 \AA$ and the in-plane HNSi angle $=124.2^{\circ}$. For HSiNH, the $\mathrm{R}_{\mathrm{NH}}$ distance is calculated to be $1.011 \AA$, the central SiN bond equals to $1.608 \AA, \mathrm{R}_{\mathrm{HSi}}=1.507 \AA$, the $\mathrm{HSiN}$ angle $=110.6^{\circ}$ and the $\mathrm{NSiH}=131.9^{\circ}$. For the less stable form (isomer III), we compute: $\mathrm{R}_{\mathrm{SiH}}=1.488 \AA, \mathrm{R}_{\mathrm{SiN}}=1.658 \AA$ and $\mathrm{HSiN}=126.5^{\circ}$. The optimized geometries with the shorter basis set (cc-pVQZ) are very close to the ones given here.

Table 2 gives the rotational constants of these three isomers at equilibrium $\left(A_{e}, B_{e}\right.$ and $\left.C_{e}\right)$ and their dipole moments $\left(\mu_{\mathrm{e}}\right)$. These radicals present relatively large dipole moments making their identification in astrophysical media feasible by radio spectroscopy. Our work should help for that purpose pursuit in our previous works about silicon molecules of astrophysical interest [30].

Table 2 lists also the harmonic wavenumbers and the infrared intensities for $\mathrm{H}_{2} \mathrm{NSi}, \mathrm{HSiNH}$ and $\mathrm{H}_{2} \mathrm{SiN}$ derived using the standard options of MOLPRO. Calculated intensities for the fundamental bands (see Table 2) can help the assignments of observations through infrared active vibrational modes. For the symmetric modes $\left(a_{1}, b_{2} \& a^{\prime}\right)$, the data obtained using the small and the more diffuse basis sets are of the same order of magnitude (differences are less than $50 \mathrm{~cm}^{-1}$ ), whereas large differences are found for the antisymmetric or for the out-of-plane torsion modes $\left(b_{1} \& a\right.$ "). This is most likely because of either the flatness of the potentials along these coordinates or because of numerical problems (symmetry breaking) not fully resolved with the smaller basis set, especially for these floppy molecular systems. Indeed, we showed previously that, for tetratomic weakly bound species, the second order perturbation theory is not fully sufficient for the prediction of their vibrational terms and one needs to go beyond this approximation i.e. to take into account anharmonic effects (more details can be found in Refs. [31-34]). Therefore, the generation of the full 6D potential energy surfaces of the three species of interest here should be performed with the incorporation of diffuse atomic orbitals and multiconfigurational $a b$ initio methods and full variational treatment of the nuclear motions. 
The isomerization process from $\mathrm{H}_{2} \mathrm{NSi}$ (I) into trans-HSiNH (II) is studied by varying the $\mathrm{z}_{1}$ distance for different $\mathrm{x}_{1}$ values. Figure 3 gives the definition of these coordinates. The calculations have been carried out at the CASSCF/MRCI/aug-cc-pVQZ level of theory because of the multiconfigurational nature of the ground doublet wavefunctions along this isomerization pathway. Figure 4 presents the potential curves for the intramolecular isomerization from trans-HSiNH (II) into $\mathrm{H}_{2} \mathrm{SiN}$ (III) for different $\mathrm{z}_{4}$ and $\mathrm{x}_{4}$ values as defined there. For each set of curves, the other internal coordinates are kept fixed at their RCCSD(T)/aug-cc-pVQZ values computed at trans-HSiNH $\left(\tilde{X}^{2} \mathrm{~A}^{\prime}\right)$ equilibrium (Table 1). Our sets of $\left(\mathrm{x}_{1}, \mathrm{z}_{1}\right)$ and $\left(\mathrm{x}_{4}, \mathrm{z}_{4}\right)$ allow mapping the 6D-PES for H-Si, $\mathrm{HSiN}$ and $\mathrm{HN}$ and SiNH internal coordinates over wide ranges for the unbroken bonds and the inplane angles around their equilibrium distances, whereas the lengthened distance (HSi in Figure 3 and HN in Figure 4) varies from -6 up to 10 bohrs. This formally corresponds to relaxation of the internal coordinates.

Figures 3 and 4 show clearly three minima corresponding to the three isomers discussed in previous section. These minima are separated by relatively high potential barriers: $\mathrm{E}_{\mathrm{I}-\mathrm{II}}$ is the isomerization potential barrier energy to convert I into to II and $\mathrm{E}_{\mathrm{II}-\mathrm{III}}$ is the isomerization potential barrier to convert II into III (and vice versa). $\mathrm{E}_{\mathrm{I}-\mathrm{II}}$ is estimated to be $2.00 \mathrm{eV}$ and $\mathrm{E}_{\mathrm{II}-\mathrm{III}}$ is calculated to be equal to $3.17 \mathrm{eV}$. Our MRCI $\mathrm{E}_{\mathrm{I}-\mathrm{II}}$ coincides with the EI-II evaluated at the MP2/6-31G** level [16], whereas our MRCI $E_{\text {II-III }}$ value is slightly larger than the MP2 value (2.4 eV) [16], and is believed to be more accurate since they are derived from multiconfigurational treatments and larger basis set than Goldberg et al.'s work [16]. In addition, secondary minima are found which may correspond to transient species of $\mathrm{HSiNH}$ (e.g. cf. curve for $\mathrm{x}_{4}=-1.45 \&$ energy $\sim 4 \mathrm{eV}$ ). This form is located at more than $2 \mathrm{eV}$ relative to the global minimum. More generally, the computed barriers are quite large. Hence, each isomer can a priori be isolated for its identification and characterization in laboratory.

In Figures 3 and 4, thick lines correspond to the local potential curves around the minimal structure of each isomer. Each of these curves describes one isomer and not three of them and they don't correspond to the lowest curve at the top of the barrier through these isomerisation pathways. Hence, these processes are accompanied by coordinate relaxation and one needs to consider the 6DPESs for their dynamical investigations.

The examination of our curves close to the $\mathrm{H}$ abstraction channels, producing $\mathrm{H}+\mathrm{SiNH}$ (channel 1) and $\mathrm{H}+\mathrm{HSiN}$ (channel 2), reveals that one needs to overcome small potential barriers of $\sim 0.15 \mathrm{eV}$ and $\sim 0.1 \mathrm{eV}$ before reaching channel 1 products valley from isomers I and II, respectively, whereas the MP2/6-31G** calculations give a direct connection of these tetratomics to their dissociation products. Smaller potential barriers (lower than $0.1 \mathrm{eV}$ ) are computed along channel 2 when dissociating isomers II or III. This confirms the MP2/6-31G** previous calculations [16]. Concerning the $\mathrm{H}$-abstraction pathway from isomer I via channel 1, it should occur along the PES of the ground state of this isomer after overcoming the potential barrier of $0.15 \mathrm{eV}$ in addition to the dissociation energy of $1.88 \mathrm{eV}$ (position of $\mathrm{H}+\mathrm{SiNH}$ asymptote). The production of $\mathrm{H}+\mathrm{HSiN}$ needs 
larger energies $(>4.75 \mathrm{eV})$ and it goes through the formation of isomer II intermediate and probably also isomer III (Figures 3 and 4). In contrast, our isomer II connects directly to channels 1 and 2 products and one needs just to overcome the eventual potential barriers discussed above. For isomer III decomposition, a direct mechanism can be proposed for the formation of $\mathrm{H}+\mathrm{HSiN}$ whereas the $\mathrm{H}$ + HNSi should go through the population of the two other more stable forms.

\section{Electronic excited states}

Tables 3, 4 and 5 list the dominant electron configuration and the vertical excitation energies of the $\mathrm{H}_{2} \mathrm{NSi}$, HSiNH and $\mathrm{H}_{2} \mathrm{SiN}$ doublet and quartet electronic states up to $6 \mathrm{eV}$. These calculations are performed at the RCCSD(T)/aug-cc-pVQZ equilibrium geometry of their respective ground states (Table 1). These energies are computed using CASSCF and MRCI methodologies and with the ccpVQZ and aug-cc-pVQZ basis sets. The CASSCF energies of these electronic states are close to those obtained after MRCI treatments. Hence, the static correlation, already included at CASSCF level, is enough for a rather good description. Moreover, the inclusion of diffuse atomic orbitals in the basis set (from cc-pVQZ to aug-cc-pVQZ) does not induce drastic change in the pattern of these electronic states signature of their valence rather than valence-Rydberg nature. Exception should be made for the $\mathrm{H}_{2} \mathrm{NSi}\left(3^{2} \mathrm{~A}_{1}\right)$ state (Table 3), which is located close to the ionization energy of this molecule [17]. Indeed, its vertical excitation energy is lowered by $\sim 1 \mathrm{eV}$ with the larger basis set.

For $\mathrm{H}_{2} \mathrm{NSi}$ and $\mathrm{H}_{2} \mathrm{SiN}$, the first excited states are the $1^{2} \mathrm{~B}_{1}$ located at $0.99 \mathrm{eV}$ and $1.37 \mathrm{eV}$, respectively (Tables 3 and 5). They correspond to the promotion of an electron from the outermost $b_{1}$ molecular orbital (MO) to the semi unoccupied $\mathrm{b}_{2}$ MO. For trans-HSiNH, the lowest excited state $\left(1^{2} \mathrm{~A} "\right)$ lies at $2.3 \mathrm{eV}$ with respect to the ground state. Therefore the electronic desexcitation of the $\mathrm{HSiNH}\left(1^{2} \mathrm{~A}\right.$ ") molecules may occur via emission of visible light or radiationless internal conversion processes. For all three isomers, the lowest quartets are located at $\sim 3.5 \mathrm{eV}$ above their corresponding ground states.

Strictly speaking, the $\mathrm{B}_{1}-\mathrm{B}_{2}$ transition (photoemission or absorption) for isomers I and II is forbidden in the $\mathrm{C}_{2 \mathrm{v}}$ point group. Nevertheless, such transition becomes slightly allowed for non symmetrical configurations $\left(\mathrm{C}_{\mathrm{s}}\right.$ or $\mathrm{C}_{1}$ point groups) i.e. after relaxation of internal coordinates. Accordingly, the unimolecular dynamics of electronically excited $\mathrm{H}_{2} \mathrm{NSi}$ and $\mathrm{H}_{2} \mathrm{SiN}$ and $\mathrm{HSiNH}$ is expected to be very complex.

Generally, a high density of electronic states is found for internal energies $>3 \mathrm{eV}$. This may favour their mutual interaction by vibronic (at their crossing and avoided crossings) and spin-orbit couplings (at their crossings). In addition, Figure 5, which depicts the one-dimensional evolution of the lowest doublet HSiNH electronic states along the trans and cis bending coordinates, shows that some of these electronic states correlate to doubly degenerate electronic representations for linear configuration. For instance, this is the case for the second ${ }^{2} \mathrm{~A}$ ' and the lowest ${ }^{2} \mathrm{~A}$ " states which 
correlate to the $1^{2} \Pi$ at linearity. Both components are coupled by Renner-Teller effect. This effect, together with spin-orbit coupling, participates to the mixing of their corresponding wavefunctions especially close to the barriers to linearity. Consequently, generation of the $6 \mathrm{D}$ potential energy surfaces of these electronic states and their corresponding rovibronic spectra is computationally challenging. Both the experimental and theoretical spectra are expected to be hard to assign.

\section{CONCLUSION}

Using $a b$ initio methodologies, we have characterized the stable forms of the astrophysically important $\mathrm{H}_{2} \mathrm{NSi}$ radicals, where two $\mathrm{C}_{2 \mathrm{v}}$ structures and a trans planar isomer are found. In particular this system does not present a stable cis structure in contrast to the isovalent $\mathrm{HCNH}$ species. This confirms once more the breakdown of the $\mathrm{C} / \mathrm{Si}$ analogy which has been point out previously.

For the stable species, we give a set of accurate spectroscopic properties, which are mostly predictive in nature. We explored also their lowest electronic states. These data are useful for the characterization of these species either isolated or trapped in cooled matrices in laboratory by means of $\mu \mathrm{w}$, IR and UV spectroscopies. This work should motivate their identification in astrophysical media and it should help for the understanding of the gas and condensed phases reactivity of silicon containing molecules and materials with ammonia and small amines.

\section{NOTE}

This project has been initiated by discussions with Pavel Rosmus during his last visit to CINECA (Bologna, Italy). We dedicate it to him.

\section{AKCNOWLEGMENTS}

The authors acknowledge the Ministerio de Ciencia e Innovación of SPAIN for the grants AYA2008-00446 and AYA2009-05801-E/AYA and to CESGA for computing facilities. 


\section{REFERENCES}

1. D. W. Hughes, in Cosmic Dust, ed. J. A. M. McDonnell, 1978.

2. J. M. C. Plane. Chem. Rev. 103, 4963 (2003).

3. C. Koeberl and E. H. Hagen. Geochim. Cosmochim. Acta 53, 937 (1989).

4. T. Vondrak, J. M. C. Plane, S. Broadley and D. Janches. Atmos. Chem. Phys. Discuss. 8, 14557 (2008).

5. J. C. Gómez Martín, M. A. Blitz and J. M. C. Plane. Phys. Chem. Chem. Phys. 11, 671 (2009).

6. J. C. Gómez Martín, M. A. Blitz and J. M. C. Plane. Phys. Chem. Chem. Phys. 11, 671 (2009).

7. E.E. Ferguson, D. W. Fahey, F. C. Fehsenfeld and D. L. Albritton. Planet. Space Sci. 29, 307, (1981).

8. B. E. Turner. ApJ. 388, L35 (1992).

9. S. Wlodek and D. K. Bohme. J. Am. Chem. Soc. 110, 2396 (1988).

10. M. J. D. Low, N. Ramasubramanian and V. V. Subba Rao. J. Phys. Chem. 71, 1726 (1997).

11. O. Parisel, M. Hanus and Y. Ellinger. Chem. Phys. 212, 331 (1996).

12. D. Y. Zhang, C. Pouchan, D. Jacquemin and E. A. Perpète. Chem. Phys. Letters 408, 226 (2005).

13. O. Parisel, M. Hanus and Y. Ellinger. J. Phys. Chem. 100, 2926 (1996).

14. O. Parisel, M. Hanus and Y. Ellinger. J. Chem. Phys. 104, 1979 (1996).

15. O. Parisel, M. Hanus and Y. Ellinger. J. Phys. Chem. A 101, 299 (1999) and references therein.

16. N. Goldberg, J. Hrusak, M. Iraqi and H. Schwarz. J. Phys. Chem. 97, 10687 (1993).

17. W.-K. Chen, I-Ch. Lu, Ch. Chaudhuri, W.-J. Huang and S.-H. Lee. J. Phys. Chem. A 112 , 8479 (2008).

18. B. S. Jursic. J. Mol. Struct. THEOCHEM 455, 77 (1998). 
19. MOLPRO, A package of ab initio programs, Werner, H.-J., \& Knowles, P. J. 2006 (see http://www.molpro.net for more details).

20. T. H. Dunning. J. Chem. Phys. 90, 1007 (1989).

21. D. E Woon and T. H. Dunning, Jr. J. Chem. Phys. 98, 1358 (1993).

22. R. A. Kendall, T. H. Dunning, Jr., and R. J. Harrison, J. Chem. Phys. 96,. 67961992.

23. P. J. Knowles, C. Hampel and H.-J. Werner. J. Chem. Phys. 99, 5219 (1993).

24. P.J. Knowles and H.-J. Werner. Chem. Phys. Lett. 115, 259 (1985).

25. H.-J. Werner and P.J. Knowles. J. Chem. Phys. 82, 5053 (1985).

26. P.J. Knowles and H.-J. Werner. Chem. Phys. Lett. 145, 514 (1988).

27. H.-J. Werner and P.J. Knowles. J. Chem. Phys. 89, 5803 (1988).

28. S.R. Langhoff and E.R. Davidson. Int. J. Quant. Chem. 8, 61 (1974).

29. C. Puzzarini and V. Barone. Chem. Phys. Letters 467, 276 (2009) and references therein.

30. N. Inostroza, M. Hochlaf, M. L. Senent and R. Letelier. A \& A 486, 1047 (2008).

31. M. Hochlaf, C. Léonard, E. E. Ferguson, P. Rosmus, E. A. Reinsch, S. Carter and N. C. Handy. J. Chem. Phys. 111, 4948 (1999).

32. C. Léonard, P. Rosmus, S. Carter and N. C. Handy. J. Phys. Chem. A 103, 1846 (1999).

33. M. Hochlaf. "Theoretical spectroscopy of tetratomic molecules". Trends in Chemical Physics 12, 1 (2005).

34. V. Brites, O. Dopfer and M. Hochlaf. J. Phys. Chem. A 112, 11283 (2008). 


\section{Figure captions}

Figure 1: One dimensional cut of the 6D potential energy surface of the ground electronic state of trans-HSiNH along the torsion $(\tau)$ angle.

Figure 2: Stable isomers of $\mathrm{H}_{2} \mathrm{SiN}$ and definition of their internal coordinates.

Figure 3: CASSCF/MRCI/aug-cc-pVQZ potential energy curves vs. $z_{1}$ for different $x_{1}$ values. These curves are given relative to the isomer I minimum. The $\mathrm{NH}$ and $\mathrm{SiN}$ distances and the in-plane $\mathrm{SiNH}$ angle are kept fixed at their RCCSD(T)/aug-VQZ values computed at trans-HSiNH ( $\left.\tilde{X}^{2} \mathrm{~A}^{\prime}\right)$ equilibrium (cf. Table 1).

Figure 4: CASSCF/MRCI/aug-cc-pVQZ potential energy curves vs. $z_{1}$ for different $x_{1}$ values. These curves are given relative to the isomer I minimum. The $\mathrm{SiH}$ and $\mathrm{SiN}$ distances and the in-plane HSiN angle are kept fixed at their RCCSD(T)/aug-VQZ values computed at trans-HSiNH ( $\left.\tilde{X}^{2} \mathrm{~A}^{\prime}\right)$ equilibrium (cf. Table 1).

Figure 5: CASSCF/MRCI/aug-cc-pVQZ one dimensional cuts of the 6D potential energy surfaces of the doublet electronic states of HSiNH vs. the trans (right side) and cis (left side) bending coordinates. The stretchings are kept set to their equilibrium values in trans-HSiNH ( $\left.\tilde{X}^{2} \mathrm{~A}^{\prime}\right)$ (Table 1). The reference energy is the energy of the ground state at linearity.

Photo: Pavel Rosmus (1938-2009). 
Table 1: Relative energy $\left(\mathrm{E}_{\mathrm{R}}\right.$, in $\left.\mathrm{eV}\right)$ and structural parameters (distances in $\AA$; angles in degrees) of $\mathrm{H}_{2} \mathrm{NSi}$ isomers. First entry is for the RCCSD(T)/cc-pVQZ data and the second entry is for the RCCSD(T)/aug cc-pVQZ results. See Figure 2 for the definition of the internal coordinates.

\begin{tabular}{|c|c|c|c|c|c|c|c|}
\hline Isomer & $\mathrm{E}_{\mathrm{R}}$ & $\mathrm{R}_{1}$ & $\mathrm{R}_{2}$ & $\mathrm{R}_{3}$ & $\theta_{1}$ & $\theta_{2}$ & $\tau$ \\
\hline \multirow{2}{*}{$\begin{array}{l}\mathrm{I}: \tilde{X}^{2} \mathrm{~B}_{2} \\
\mathrm{C}_{2 \mathrm{v}}\end{array}$} & & 1.012 & 1.012 & 1.711 & 124.4 & 124.4 & 0 \\
\hline & $0.0^{\text {a) }}$ & 1.010 & 1.010 & 1.712 & 124.2 & 124.2 & 0 \\
\hline \multirow[t]{2}{*}{ II: $\tilde{X}^{2} \mathrm{~A}^{\prime}$} & & 1.509 & 1.609 & 1.011 & 110.3 & 131.7 & 180 \\
\hline & 0.68 & 1.507 & 1.608 & 1.009 & 110.6 & 131.9 & 180 \\
\hline \multirow{2}{*}{$\begin{array}{l}\text { III: } \tilde{X}^{2} \mathrm{~B}_{2} \\
\mathrm{C}_{2 \mathrm{v}}\end{array}$} & & 1.488 & 1.488 & 1.654 & 127.0 & 127.0 & 0 \\
\hline & 1.88 & 1.489 & 1.489 & 1.658 & 126.5 & 126.5 & 0 \\
\hline
\end{tabular}

a) Used as reference. 
Table 2: Equilibrium rotational constants $\left(A_{e}, B_{e}\right.$ and $C_{e}$, in $\left.\mathrm{cm}^{-1}\right)$, harmonic wavenumbers $\left(\omega_{i}\right.$, in $\mathrm{cm}^{-}$ ${ }^{1}$ ) and dipole moment ( $\mu_{\mathrm{e}}$, in Debye) of $\mathrm{H}_{2} \mathrm{NSi}$ isomers. First entry is for the RCCSD(T)/cc-pVQZ data and the second entry is for the RCCSD(T)/aug cc-pVQZ results. In italic, the IR intensities are defined in Debyes ${ }^{2} / \AA^{2}$ amu.

\begin{tabular}{|c|c|c|c|c|c|c|c|c|c|c|}
\hline Isomer & $\mathrm{A}_{\mathrm{e}}$ & $\mathrm{B}_{\mathrm{e}}$ & $\overline{C_{e}}$ & $\omega_{1}$ & $\omega_{2}$ & $\omega_{3}$ & $\omega_{4}$ & $\omega_{5}$ & $\omega_{6}$ & $\mu_{\mathrm{e}}$ \\
\hline $\mathrm{H}_{2} \mathrm{NSi}$ (I) & $\begin{array}{l}12.0005 \\
11.9936\end{array}$ & $\begin{array}{l}0.5113 \\
0.5104\end{array}$ & 0.4896 & $\begin{array}{l}3606.5 \\
\left(a_{1}\right) \\
3533.3 \\
20\end{array}$ & $\begin{array}{l}1481.9 \\
\left(a_{1}\right) \\
1585.0 \\
7\end{array}$ & $\begin{array}{l}922.5 \\
\left(a_{1}\right) \\
729.8 \\
33\end{array}$ & $\begin{array}{l}838.9 \\
\left(b_{1}\right) \\
564.8 \\
100\end{array}$ & $\begin{array}{l}3717.4 \\
\left(b_{2}\right) \\
3626.5 \\
16\end{array}$ & $\begin{array}{l}884.7 \\
\left(b_{2}\right) \\
865.1 \\
3\end{array}$ & 2.19 \\
\hline HSiNH (II) & 7.4773 & 0.5879 & $\begin{array}{l}0.5447 \\
0.5445\end{array}$ & $\begin{array}{l}3693.4 \\
\left(a^{\prime}\right) \\
3638.3 \\
25\end{array}$ & $\begin{array}{l}2085.3 \\
\left(a^{\prime}\right) \\
2058.3 \\
100\end{array}$ & $\begin{array}{l}1138.6 \\
\left(a^{\prime}\right) \\
1066.9 \\
8\end{array}$ & $\begin{array}{l}778.2 \\
\left(a^{\prime}\right) \\
726.1 \\
38\end{array}$ & $\begin{array}{l}445.1 \\
(\mathrm{a}) \\
639.0 \\
100\end{array}$ & $\begin{array}{l}636.0 \\
(\mathrm{a}) \\
524.0 \\
40\end{array}$ & 1.58 \\
\hline $\mathrm{H}_{2} \mathrm{SiN}$ (III) & 5.8375 & 0.5696 & 0.5196 & $\begin{array}{l}2210.3 \\
\left(a_{1}\right) \\
2196.0 \\
27\end{array}$ & $\begin{array}{l}1050.4 \\
\left(a_{1}\right) \\
1074.1 \\
32\end{array}$ & $\begin{array}{l}959.1 \\
\left(a_{1}\right) \\
975.3 \\
29\end{array}$ & $\begin{array}{l}718.5 \\
\left(b_{1}\right) \\
509.7 \\
9\end{array}$ & $\begin{array}{l}2232.3 \\
\left(b_{2}\right) \\
2195.6 \\
100\end{array}$ & $\begin{array}{l}709.2 \\
\left(b_{2}\right) \\
631.5 \\
62\end{array}$ & 3.37 \\
\hline
\end{tabular}


Table 3: Pattern of the lowest doublet and quartet electronic states of isomer I computed at the $\operatorname{RCCSD}(\mathrm{T}) /$ aug-cc-pVQZ equilibrium geometry of the ground state. Energies are in eV. We also give their dominant electron configuration.

\begin{tabular}{|l|l|l|l|l|l|}
\hline State & Dominant electron configuration & $\begin{array}{l}\text { CASSCF/cc- } \\
\text { pVQZ }\end{array}$ & $\begin{array}{l}\text { MRCI/cc- } \\
\text { pVQZ }\end{array}$ & $\begin{array}{l}\text { CASSCF/aug- } \\
\text { cc-pVQZ }\end{array}$ & $\begin{array}{l}\text { MRCI/aug- } \\
\text { cc-pVQZ }\end{array}$ \\
\hline$\tilde{X}^{2} \mathrm{~B}_{2}$ & $\left(5 \mathrm{a}_{1}\right)^{2}\left(6 \mathrm{a}_{1}\right)^{2}\left(2 \mathrm{~b}_{2}\right)^{2}\left(2 \mathrm{~b}_{1}\right)^{2}\left(7 \mathrm{a}_{1}\right)^{2}\left(3 \mathrm{~b}_{2}\right)^{1}$ & $0.00^{\mathrm{a})}$ & $0.00^{\mathrm{a})}$ & $0.00^{\mathrm{a})}$ & $0.000^{\mathrm{a})}$ \\
\hline $1^{2} \mathrm{~B}_{1}$ & $\left(5 \mathrm{a}_{1}\right)^{2}\left(6 \mathrm{a}_{1}\right)^{2}\left(2 \mathrm{~b}_{2}\right)^{2}\left(2 \mathrm{~b}_{1}\right)^{2}\left(7 \mathrm{a}_{1}\right)^{2}\left(3 \mathrm{~b}_{1}\right)^{1}$ & 1.21 & 1.00 & 1.17 & 0.99 \\
\hline $1^{4} \mathrm{~A}_{2}$ & $\left(5 \mathrm{a}_{1}\right)^{2}\left(6 \mathrm{a}_{1}\right)^{2}\left(2 \mathrm{~b}_{2}\right)^{2}\left(2 \mathrm{~b}_{1}\right)^{2}\left(7 \mathrm{a}_{1}\right)^{1}\left(3 \mathrm{~b}_{2}\right)^{1}\left(3 \mathrm{~b}_{1}\right)^{1}$ & 3.73 & 3.56 & 4.26 & 3.70 \\
\hline $1^{2} \mathrm{~A}_{1}$ & $\left(5 \mathrm{a}_{1}\right)^{2}\left(6 \mathrm{a}_{1}\right)^{2}\left(2 \mathrm{~b}_{2}\right)^{2}\left(2 \mathrm{~b}_{1}\right)^{2}\left(7 \mathrm{a}_{1}\right)^{2}\left(8 \mathrm{a}_{1}\right)^{1}$ & 4.08 & 3.68 & 2.96 & 3.18 \\
\hline $2^{2} \mathrm{~A}_{1}$ & $\left(5 \mathrm{a}_{1}\right)^{2}\left(6 \mathrm{a}_{1}\right)^{2}\left(2 \mathrm{~b}_{2}\right)^{2}\left(2 \mathrm{~b}_{1}\right)^{2}\left(7 \mathrm{a}_{1}\right)^{1}\left(3 \mathrm{~b}_{2}\right)^{2}$ & 5.18 & 4.79 & 4.84 & 4.65 \\
\hline $1^{4} \mathrm{~B}_{2}$ & $\left(5 \mathrm{a}_{1}\right)^{2}\left(6 \mathrm{a}_{1}\right)^{2}\left(2 \mathrm{~b}_{2}\right)^{2}\left(2 \mathrm{~b}_{1}\right)^{1}\left(7 \mathrm{a}_{1}\right)^{2}\left(3 \mathrm{~b}_{2}\right)^{1}\left(3 \mathrm{~b}_{1}\right)^{1}$ & 4.635 & 4.95 & 5.43 & 5.16 \\
\hline $1^{2} \mathrm{~A}_{2}$ & $\left(5 \mathrm{a}_{1}\right)^{2}\left(6 \mathrm{a}_{1}\right)^{2}\left(2 \mathrm{~b}_{2}\right)^{2}\left(2 \mathrm{~b}_{1}\right)^{2}\left(7 \mathrm{a}_{1}\right)^{1}\left(3 \mathrm{~b}_{2}\right)^{1}\left(3 \mathrm{~b}_{1}\right)^{1}$ & 5.56 & 5.22 & 5.52 & 5.20 \\
\hline $2^{2} \mathrm{~B}_{2}$ & $\left(5 \mathrm{a}_{1}\right)^{2}\left(6 \mathrm{a}_{1}\right)^{2}\left(2 \mathrm{~b}_{2}\right)^{2}\left(2 \mathrm{~b}_{1}\right)^{1}\left(7 \mathrm{a}_{1}\right)^{2}\left(3 \mathrm{~b}_{2}\right)^{1}\left(3 \mathrm{~b}_{1}\right)^{1}$ & 5.31 & 5.48 & 5.39 & 5.51 \\
\hline $2^{2} \mathrm{~B}_{1}$ & $\left(5 \mathrm{a}_{1}\right)^{2}\left(6 \mathrm{a}_{1}\right)^{2}\left(2 \mathrm{~b}_{2}\right)^{2}\left(2 \mathrm{~b}_{1}\right)^{1}\left(7 \mathrm{a}_{1}\right)^{2}\left(3 \mathrm{~b}_{2}\right)^{2}$ & 5.32 & 5.50 & 5.52 & 5.55 \\
\hline $3^{2} \mathrm{~A}_{1}$ & $\left(5 \mathrm{a}_{1}\right)^{2}\left(6 \mathrm{a}_{1}\right)^{2}\left(2 \mathrm{~b}_{2}\right)^{2}\left(2 \mathrm{~b}_{1}\right)^{2}\left(7 \mathrm{a}_{1}\right)^{1}\left(3 \mathrm{~b}_{1}\right)^{2}$ & & 6.68 & 6.45 & \\
\hline & $\&\left(5 \mathrm{a}_{1}\right)^{2}\left(6 \mathrm{a}_{1}\right)^{2}\left(2 \mathrm{~b}_{2}\right)^{2}\left(2 \mathrm{~b}_{1}\right)^{2}\left(7 \mathrm{a}_{1}\right)^{2}\left(9 \mathrm{a}_{1}\right)^{1}$ & 7.16 & & & \\
\hline
\end{tabular}

a) Used as reference. 
Table 4: Pattern of the lowest doublet and quartet electronic states of isomer II computed at the $\operatorname{RCCSD}(\mathrm{T}) /$ aug-cc-pVQZ equilibrium geometry of the ground state. Energies are in $\mathrm{eV}$. We also give their dominant electron configuration.

\begin{tabular}{|l|l|l|l|l|l|}
\hline State & $\begin{array}{l}\text { Dominant electron } \\
\text { configuration }\end{array}$ & $\begin{array}{l}\text { CASSCF/cc- } \\
\text { pVQZ }\end{array}$ & $\begin{array}{l}\text { MRCI/cc- } \\
\text { pVQZ }\end{array}$ & $\begin{array}{l}\text { CASSCF/aug- } \\
\text { cc-pVQZ }\end{array}$ & $\begin{array}{l}\text { CASSCF/aug- } \\
\text { cc-pVQZ }\end{array}$ \\
\hline$\tilde{X}^{2} \mathrm{~A}^{\prime}$ & $\left(9 \mathrm{a}^{\prime}\right)^{2}\left(2 \mathrm{a}^{\prime \prime}\right)^{2}\left(10 \mathrm{a}^{\prime}\right)^{1}$ & $0.00^{\mathrm{a})}$ & $0.00^{\mathrm{a})}$ & $0.00^{\mathrm{a})}$ & $0.00^{\mathrm{a})}$ \\
\hline $1^{2} \mathrm{~A}^{\prime \prime}$ & $\left(9 \mathrm{a}^{\prime}\right)^{2}\left(2 \mathrm{a}^{\prime \prime}\right)^{1}\left(10 \mathrm{a}^{\prime}\right)^{2}$ & 2.27 & 2.32 & 2.22 & 2.31 \\
\hline $2^{2} \mathrm{~A}^{\prime \prime}$ & $\left(9 \mathrm{a}^{\prime}\right)^{2}\left(2 \mathrm{a}^{\prime \prime}\right)^{2}\left(3 \mathrm{a}^{\prime}\right)^{1}$ & 2.91 & 2.69 & 2.94 & 2.69 \\
\hline $2^{2} \mathrm{~A}^{\prime}$ & $\left(9 \mathrm{a}^{\prime}\right)^{1}\left(2 \mathrm{a}^{\prime \prime}\right)^{2}\left(10 \mathrm{a}^{\prime}\right)^{2}$ & 2.98 & 2.94 & 2.96 & 3.93 \\
\hline $1^{4} \mathrm{~A}^{\prime}$ & $\left(9 \mathrm{a}^{\prime}\right)^{2}\left(2 \mathrm{a}^{\prime \prime}\right)^{1}\left(10 \mathrm{a}^{\prime}\right)^{1}\left(3 \mathrm{a}^{\prime \prime}\right)^{1}$ & 3.58 & 3.49 & 3.66 & 4.20 \\
\hline $1^{4} \mathrm{~A}^{\prime \prime}$ & $\left(9 \mathrm{a}^{\prime}\right)^{1}\left(2 \mathrm{a}^{\prime \prime}\right)^{2}\left(10 \mathrm{a}^{\prime}\right)^{1}\left(3 \mathrm{a}^{\prime \prime}\right)^{1}$ & 4.32 & 4.21 & 4.39 & 4.65 \\
\hline $3^{2} \mathrm{~A}^{\prime}$ & $\left(9 \mathrm{a}^{\prime}\right)^{2}\left(2 \mathrm{a}^{\prime}\right)^{1}\left(10 \mathrm{a}^{\prime}\right)^{1}\left(3 \mathrm{a}^{\prime \prime}\right)^{1}$ & 4.88 & 4.67 & 4.86 & 5.17 \\
\hline $4^{2} \mathrm{~A}^{\prime}$ & $\left(9 \mathrm{a}^{\prime}\right)^{2}\left(2 \mathrm{a}^{\prime \prime}\right)^{2}\left(11 \mathrm{a}^{\prime}\right)^{1}$ & 5.57 & 5.30 & 5.46 & 5.40 \\
\hline $3^{2} \mathrm{~A}^{\prime \prime}$ & $\left(9 \mathrm{a}^{\prime}\right)^{1}\left(2 \mathrm{a}^{\prime \prime}\right)^{2}\left(10 \mathrm{a}^{\prime}\right)^{1}\left(3 \mathrm{a}^{\prime \prime}\right)^{1}$ & 5.40 & 5.40 & 5.89 & \\
\hline
\end{tabular}

a) Used as reference. 
Table 5: Pattern of the lowest doublet and quartet electronic states of isomer III computed at the RCCSD(T)/aug-cc-pVQZ equilibrium geometry of the ground state. Energies are in eV. We also give their dominant electron configuration.

\begin{tabular}{|c|c|c|c|c|c|}
\hline State & Dominant electron configuration & $\begin{array}{l}\text { CASSCF/cc- } \\
\text { pVQZ }\end{array}$ & $\begin{array}{l}\text { MRCI/cc- } \\
\text { pVQZ }\end{array}$ & $\begin{array}{l}\text { CASSCF/cc- } \\
\text { pVQZ }\end{array}$ & $\begin{array}{l}\text { MRCI/cc- } \\
\text { pVQZ }\end{array}$ \\
\hline$\tilde{X}^{2} \mathrm{~B}_{2}$ & $\left(5 a_{1}\right)^{2}\left(6 a_{1}\right)^{2}\left(2 b_{2}\right)^{2}\left(7 a_{1}\right)^{2}\left(2 b_{1}\right)^{2}\left(3 b_{2}\right)^{1}$ & $0.00^{\text {a) }}$ & $0.00^{\mathrm{a})}$ & $0.00^{\mathrm{a})}$ & $0.00^{\text {a) }}$ \\
\hline $1^{2} \mathrm{~B}_{1}$ & $\left(5 a_{1}\right)^{2}\left(6 a_{1}\right)^{2}\left(2 b_{2}\right)^{2}\left(7 a_{1}\right)^{2}\left(2 b_{1}\right)^{1}\left(3 b_{2}\right)^{2}$ & 1.41 & 1.36 & 1.50 & 1.37 \\
\hline $1^{2} \mathrm{~A}_{1}$ & $\left(5 a_{1}\right)^{2}\left(6 a_{1}\right)^{2}\left(2 b_{2}\right)^{2}\left(7 a_{1}\right)^{1}\left(2 b_{1}\right)^{2}\left(3 b_{2}\right)^{2}$ & 1.85 & 1.85 & 1.84 & 1.84 \\
\hline $1^{4} \mathrm{~B}_{2}$ & $\left(5 a_{1}\right)^{2}\left(6 a_{1}\right)^{2}\left(2 b_{2}\right)^{2}\left(7 a_{1}\right)^{2}\left(2 b_{1}\right)^{1}\left(3 b_{2}\right)^{1}\left(3 b_{1}\right)^{1}$ & 3.02 & 2.90 & 2.72 & 2.82 \\
\hline $2^{2} \mathrm{~B}_{2}$ & $\left(5 a_{1}\right)^{2}\left(6 a_{1}\right)^{2}\left(2 b_{2}\right)^{2}\left(7 a_{1}\right)^{2}\left(2 b_{1}\right)^{1}\left(3 b_{2}\right)^{1}\left(3 b_{1}\right)^{1}$ & 3.90 & 3.91 & 3.84 & 3.88 \\
\hline $1^{4} \mathrm{~A}_{2}$ & $\left(5 a_{1}\right)^{2}\left(6 a_{1}\right)^{2}\left(2 b_{2}\right)^{2}\left(7 a_{1}\right)^{1}\left(2 b_{1}\right)^{2}\left(3 b_{2}\right)^{1}\left(3 b_{1}\right)^{1}$ & 4.38 & 4.17 & 4.09 & 4.10 \\
\hline $2^{2} \mathrm{~B}_{1}$ & $\left(5 a_{1}\right)^{2}\left(6 a_{1}\right)^{2}\left(2 b_{2}\right)^{2}\left(7 a_{1}\right)^{2}\left(2 b_{1}\right)^{2}\left(3 b_{1}\right)^{1}$ & 4.30 & 4.19 & 4.14 & 4.15 \\
\hline $1^{2} \mathrm{~A}_{2}$ & $\left(5 a_{1}\right)^{2}\left(6 a_{1}\right)^{2}\left(2 b_{2}\right)^{2}\left(7 a_{1}\right)^{1}\left(2 b_{1}\right)^{2}\left(3 b_{2}\right)^{1}\left(3 b_{1}\right)^{1}$ & 4.57 & 4.54 & 4.37 & 4.49 \\
\hline $1^{4} \mathrm{~A}_{1}$ & $\left(5 a_{1}\right)^{2}\left(6 a_{1}\right)^{2}\left(2 b_{2}\right)^{2}\left(7 a_{1}\right)^{1}\left(2 b_{1}\right)^{1}\left(3 b_{2}\right)^{2}\left(3 b_{1}\right)^{1}$ & 4.74 & 4.63 & 4.44 & 4.54 \\
\hline $3^{2} \mathrm{~B}_{2}$ & $\begin{array}{l}\left(5 a_{1}\right)^{2}\left(6 a_{1}\right)^{2}\left(2 b_{2}\right)^{2}\left(7 a_{1}\right)^{2}\left(2 b_{1}\right)^{1}\left(3 b_{2}\right)^{1}\left(3 b_{1}\right)^{1} \\
\&\left(5 a_{1}\right)^{2}\left(6 a_{1}\right)^{2}\left(2 b_{2}\right)^{1}\left(7 a_{1}\right)^{2}\left(2 b_{1}\right)^{2}\left(3 b_{2}\right)^{2}\end{array}$ & 5.70 & 5.30 & 5.56 & 5.24 \\
\hline $2^{4} \mathrm{~A}_{2}$ & $\left(5 a_{1}\right)^{2}\left(6 a_{1}\right)^{2}\left(2 b_{2}\right)^{2}\left(7 a_{1}\right)^{2}\left(2 b_{1}\right)^{1}\left(3 b_{2}\right)^{1}\left(8 a_{1}\right)^{1}$ & 6.00 & 5.60 & 5.64 & 5.43 \\
\hline $3^{2} \mathrm{~B}_{1}$ & $\left(5 a_{1}\right)^{2}\left(6 a_{1}\right)^{2}\left(2 b_{2}\right)^{2}\left(7 a_{1}\right)^{2}\left(3 b_{2}\right)^{2}\left(3 b_{1}\right)^{1}$ & 5.79 & 5.79 & 5.79 & 5.75 \\
\hline $2^{2} \mathrm{~A}_{1}$ & $\left(5 a_{1}\right)^{2}\left(6 a_{1}\right)^{2}\left(2 b_{2}\right)^{2}\left(7 a_{1}\right)^{1}\left(2 b_{1}\right)^{1}\left(3 b_{2}\right)^{2}\left(3 b_{1}\right)^{1}$ & 5.92 & 5.89 & 5.87 & 5.87 \\
\hline
\end{tabular}

a) Used as reference. 
Figure 1

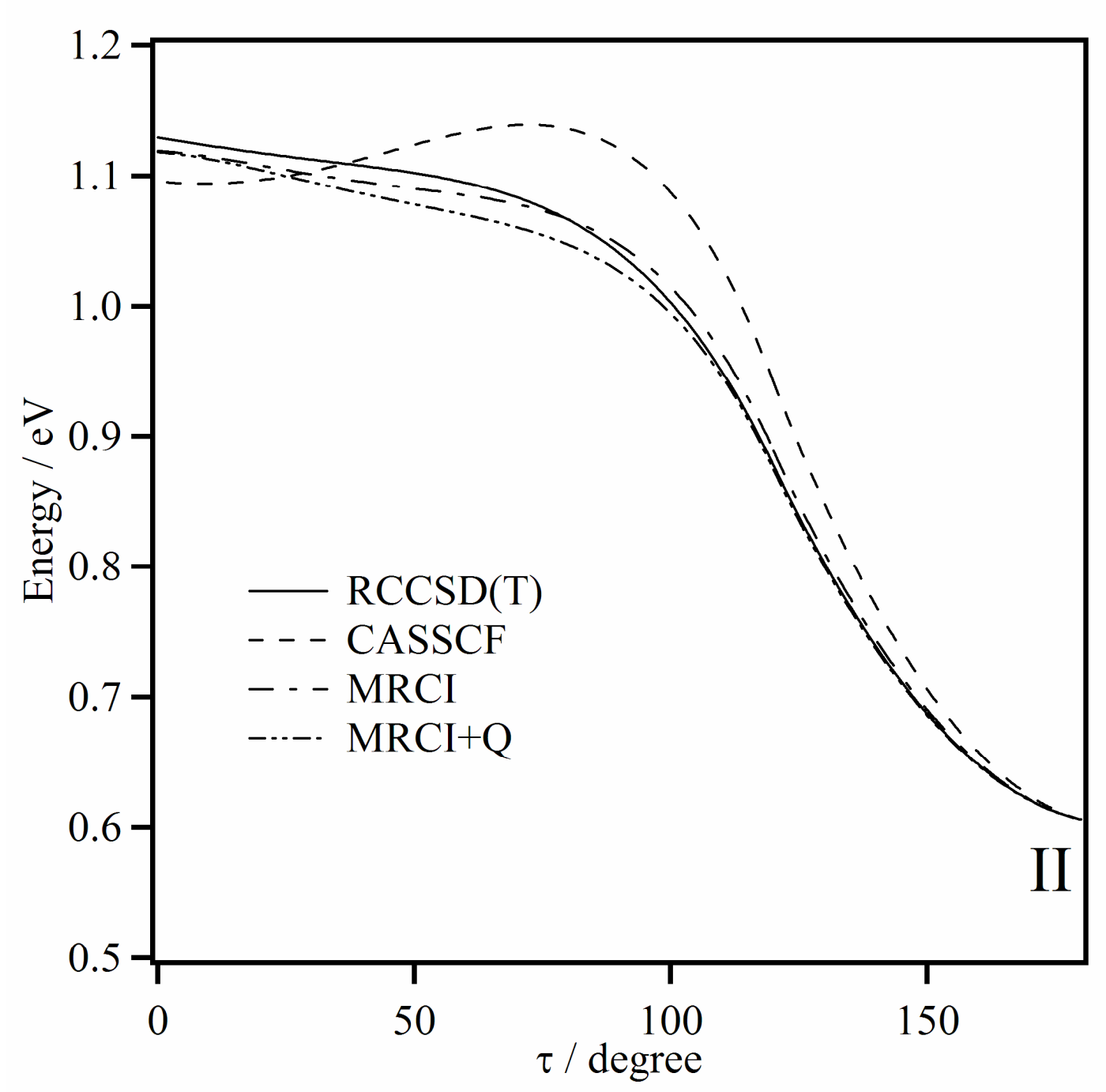


Figure 2

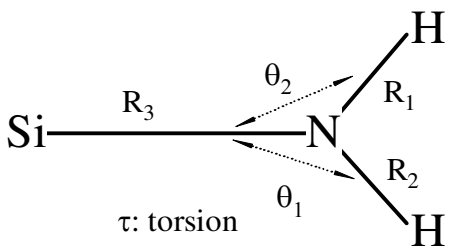

Isomer I

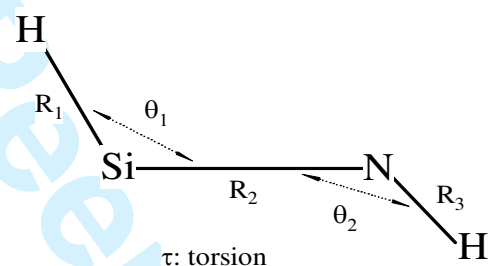

Isomer II

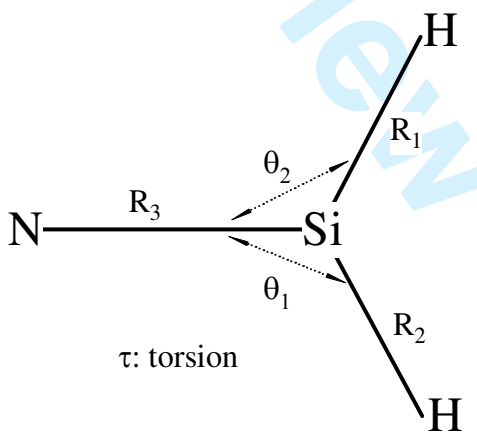

Isomer III 


\section{Figure 3}

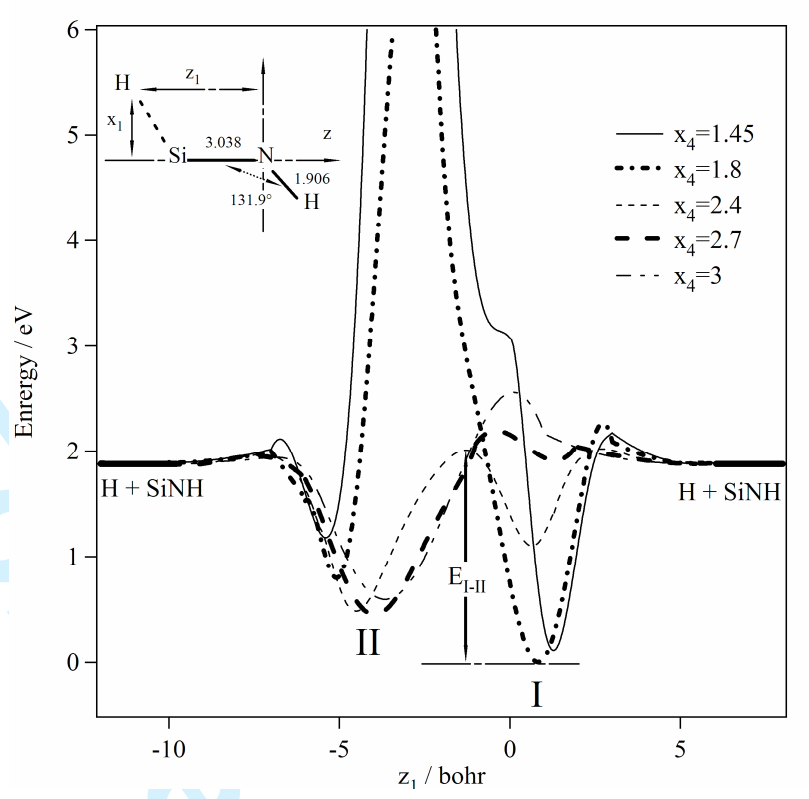

1

3 4 
Figure 4

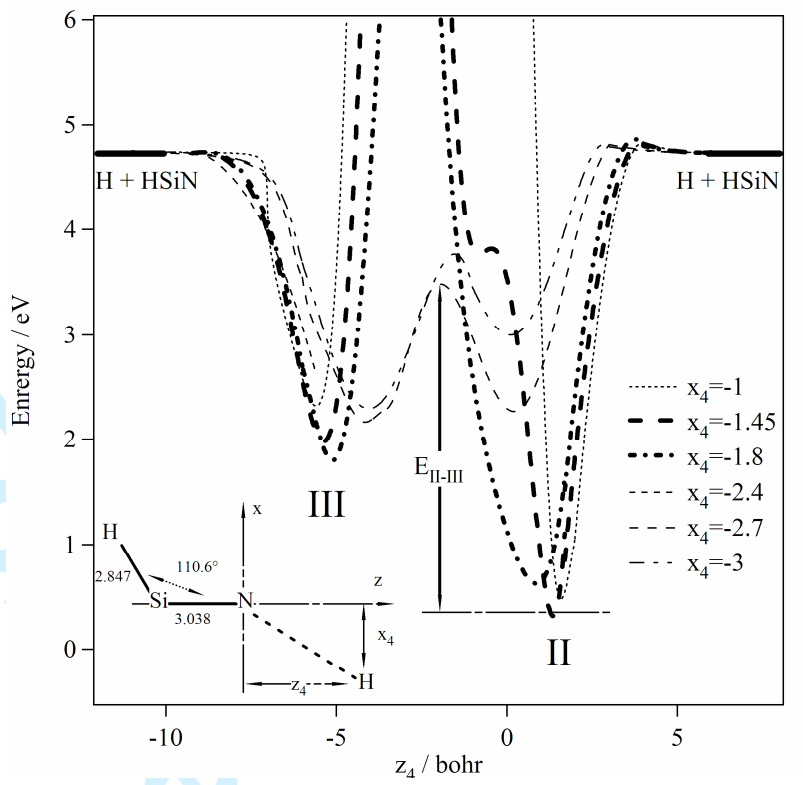


Figure 5

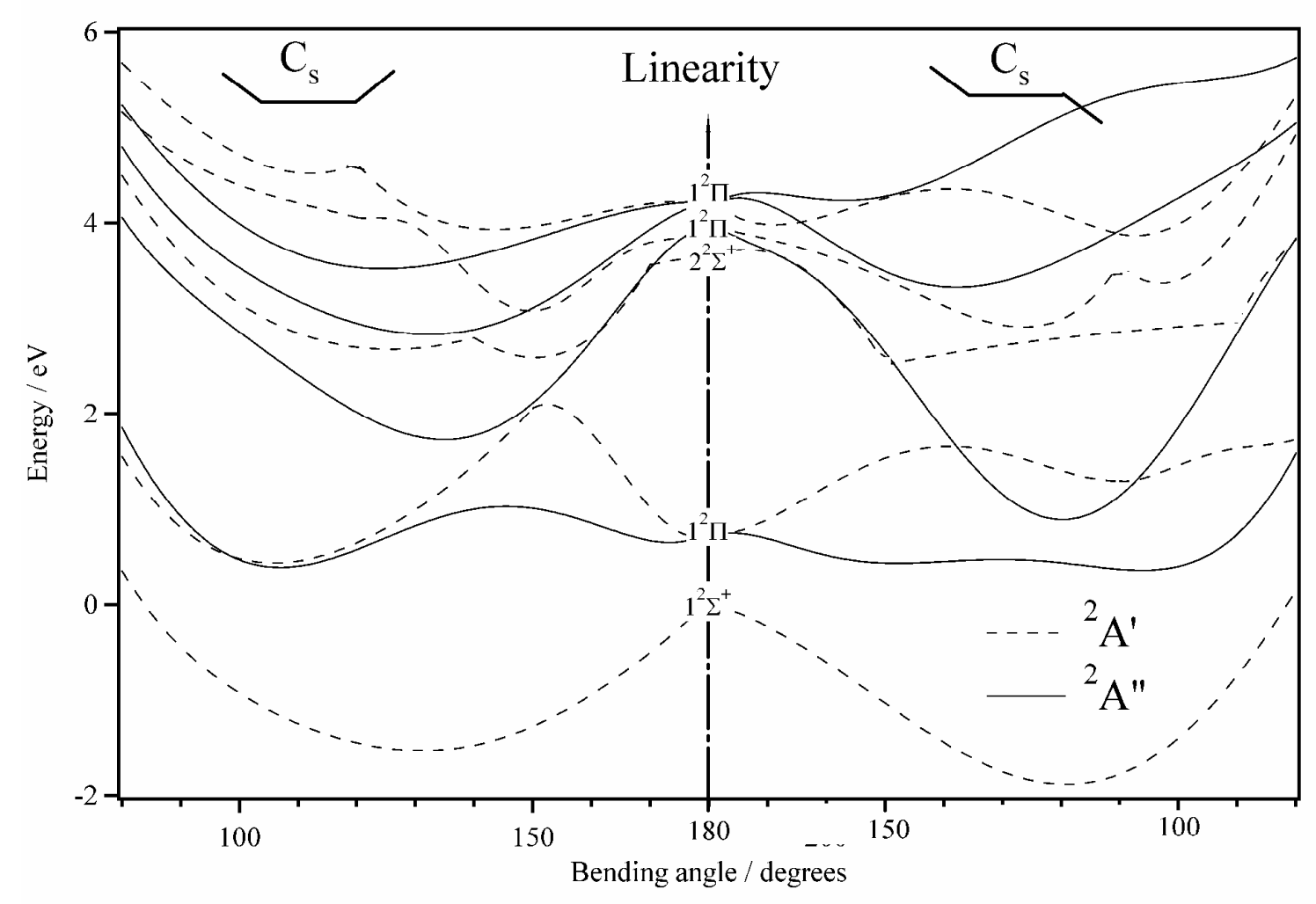




\section{Photo}

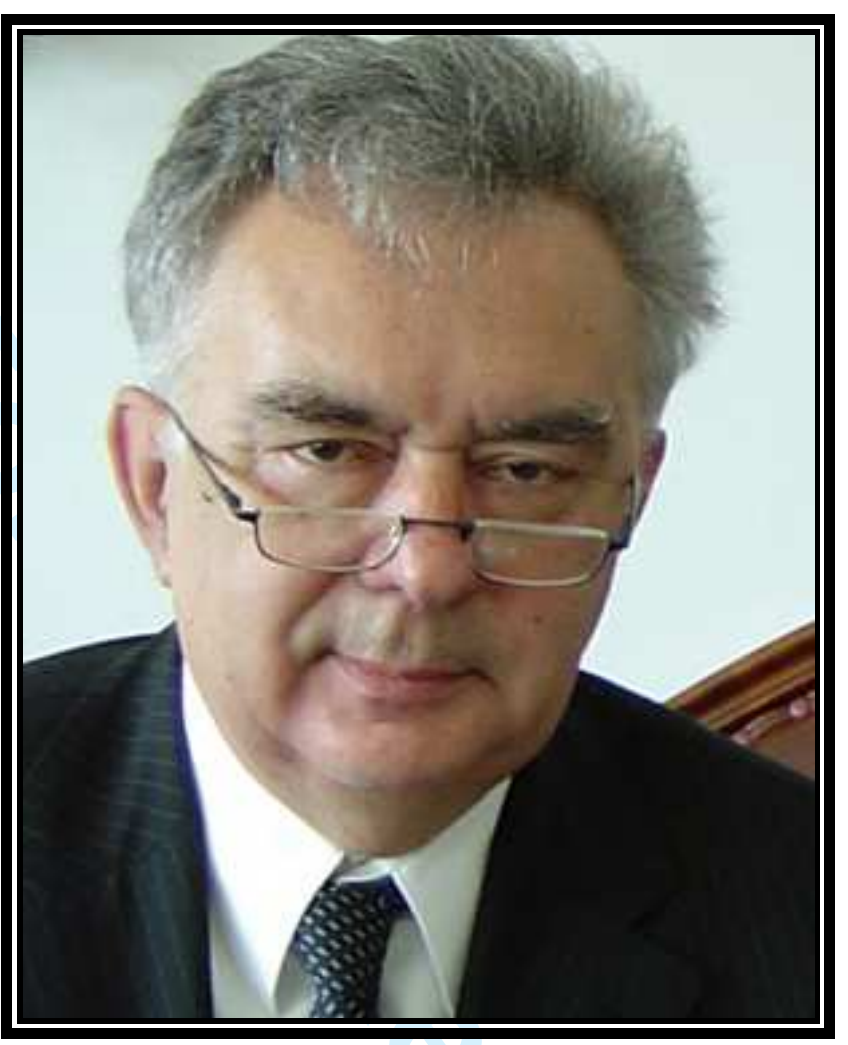

